\title{
THE EFFECT OF SPLIT SQUAT JUMP AND LATERAL BOX PUSH OFF EXERCISES ON THE SPEED OF FRONT KICK
}

\author{
(Experimental Studies on Wushu Athletes in FIK Universitas Negeri Padang) \\ Umar $^{1}$, Alnedral ${ }^{1}$, Gande Mutia Miselza ${ }^{1}$ \\ ${ }^{1}$ Faculty of Sports Science, Universitas Negeri Padang \\ 1umarmardesia@gmail.com, alnedral1960@gmail.com
}

\begin{abstract}
The purpose of this study is to evaluate the effect of split squat jump and lateral box push off exercises on front kick speed of wushu athletes of Faculty of Sports Science, Padang State University. This research is a quasi-experimental research. The free variable consists of a split squat jump exercise and a lateral box push off, while the dependent variable is the speed of the wushu front kick. The population of this study are 27 wushu athletes in Faculty of Sports Science, Padang State University. The research sample consisted of 16 male athletes with purposive sampling technique. After the pre-test, both groups were given exercise 16 times with exercise prequention 3 times per week. Group 1 of 8 people were given the practice of split squat jump training, while group 2 of 8 people were given lateral box push off training. The research instrument is a front kick speed test, using petching facets and stop watch. Data obtained from pretest and post-test were analyzed by t-test at significance level $\alpha=0.05$. Based on the data analysis, it was found that group 1 with split squat jump exercise had a significant effect on increasing front kick speed, $\mathrm{t}_{\text {count }}=2.53>\mathrm{t}_{\mathrm{table}}=1.86$. Group 2 with lateral box exercise push off also affect the increase of front kick speed, $t_{\text {count }}=2.61>t_{\text {table }}=1.86$. While between the two forms of exercise there is no different effect on the front kick speed, $t_{\text {count }}=0.19<t_{\text {tabel }}=1.86$. Both forms of split squat jump and lateral box push off exercises significantly influence the increase in front kick speed. While between the two forms of this exercise there is no difference in effect to increase the speed of the front kick.
\end{abstract}

Keywords : front kick speed, split squat jump, whusu Martial Art, and lateral box push offs

\section{Introduction}

Wushu is the collective name of all martial arts from China that is currently practiced as a sport. Wushu is the world's oldest martial arts sport originally from China. According to Louw Tjhing Houw in Sugiono (2009: 30) "all ancient martial arts originated from China that is Wushu, yet in the martial arts philosophy still recognizes that Wushu is the oldest sport". According to Kurniawan (2012: 176) "Wushu is a sport from China, where the Wushu understanding contains aspects of art, sport, martial arts, and health, Wu is war, shu is art". Meanwhile, according to Sugiarto in Sugiono (2009: 6) "Wushu in Indonesia previously known as Kuntao and in the world known as Kungfu, which is a martial art that has a history of thousands of years and is a valuable cultural heritage of China."

Tjhing Houw in Sugiono (2009: 36) says the most important basic kick technique in Wushu are as follows: 1) Tanti, is front kick, when the leg is kicking forward and the hitting is on the tip of the foot. 2) Cechuitui, the side kick, the leg's position is slightly tilted, the position of the body 
sideways, what hits the target is the area of the back foot. 3) Tengkong Feijiao the back kick forward, the position of the legs and body is like doing a kick forward, the back foot hits the target. 4) Xietitui, is the cross or diagonal kicks. this kicking position is the same as a side kick, but the shape of the foot is different from the side kick. This kick is hitting from knee to toe. The invasion of the foot is the heel area. 5) Waibaitui, is the outward kick. This kick can also be interpreted as a back kick. 6) Lihetui, the kick inward. this kick position is the same as the forward kick, but the swing is straight up and press down with the legs on the heel. 7) Chaitui, which is a trap kick or a straight kick with a sideways position in the air, which is every legs kicking always alternating rapidly on the left leg and right foot. Usually the kick can be termed for Wushu athletes as a kick without a shadow. 8) Tan Pa Ciau, is a swooping kick, this kick is the same as Chaitui kicks, but the difference is in the trap kick. This kick uses only one strong leg.

Wushu is one of the martial arts that competes in regional, national and international levels. Wushu consists of two categories: Taolu (race or art) and Sanda / sanshou (fight or free fight). Wushu has the ability to attack and defense in martial arts skills. The attack technique consists of punches (Quan) and kicks (Cechi). As for the technique of defense there are two forms of the hand defense (Tan Quen) and the limb defense (Tan Cechi). In addition there is also a technique known as Phu. All martial arts techniques in the Wushu sport such as punching, kicking, kickback, horse and so on need strength, speed, Power and good physical endurance, therefore a proper practice is needed to improve achievements of Wushu athletes.

One sasana in Provincial Board (pengprov) of Wushu in West Sumatra is sasana Wushu of Faculty of Sports Science in Padang State University. Although sasana Wushu FIK UNP has been established for a long time, but in terms of achievement it is still low. The low achievement of athletes sasana wushu FIK UNP is caused by many factors. One of them is caused by the low ability of front kick (tanti).

According to Lubis (2004: 12) "Front/straight kick is an attack that uses one foot and leg, the way is forward to the front with the position of the body facing forward, hit by the inner toe on the pit target ". Suryadi in Sugiono (2009: 8) stated, at the time of kicking a contraction of the body is required so that the power is focused on the kick and it needs a strong kick or thrust.

Front kick (tanti), is one form of attack with higher points when compared with a punch attack (boxing). The front kick gets 2 points, while the punch (boxing) earns 1 point. In addition, the attack with the front kick is dangerous enough, so it can disturb or open the opponent's defense, and good kick (tanti) is a quick kick and difficult to catch by the opponent . Therefore, in every Wushu (Sanshou / Sanda) competitions, the athletes are mostly using the front kick rather than using a punch in attempt to gain victory by winning a number or winning by Knock Out (KO).

To get a good kick (tanti) proper techniques and training methods is required, so that the front kick (tanti) can be done strongly and quickly and not easily captured or avoided by the opponent. There are many training methods that can be used to improve the skills of the wushu athletes' tanti. One of them is the plyometrics practice method that consists of various forms of exercise. Some basic movements of Plyometrics exercise for pelvic muscle groups and leg muscles are: Bounding (Doubel Leg Bound, Lateral Box Push Off, Alternate Leg Bound), Hopping (Hurdle Hopping, Split Squat Jump, Double Leg Speed Hop, Deadine Hop) Radcliffe and Forentinos (1985: 3).

From some form of exercises on Plyometrics, exercises that can be used to improve the speed of the front kick (tanti) are Split Squat Jump and Lateral Box Push Offs exercises. These two forms of exercise are very easy to do, these two forms of Plyometrics exercise both have a target in the formation of leg muscles that fit the muscle for the front kick, and these two forms of exercise do not cost much. 
According to James Radcliffe and Robert Farentinos (1985: 59), the practice of Split Squat Jump is an exercise that has a special movement to increase the explosive power of lower leg muscles and the form of training leads to the form of Bound, Jump and Hop exercises. Split squat jump is a plyometrics exercise that targets hamstrings, quadriceps, and gluteus muscles.
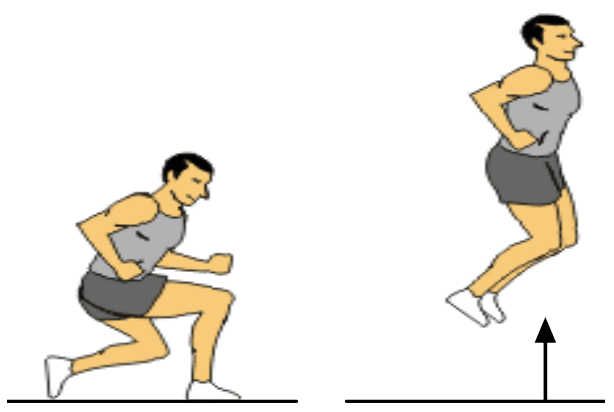

Figure 1. Split Squat Jump Exercises

Source; https://www.pliometrik+split+squat+jump

While the practice of Lateral Box Push Offs using box to be jumped over by athletes. The body position and movement is sideways with the position of one foot above the box, then the feet above the box exchanged each jump. Lateral Training Box Push Offs is a form of training to train and improve the endurance component, leg muscle power. Rodecliff and Forentinos (1985: 69) says on the Lateral Box Push Offs exercise: Lateral Training Box Push Offs begins in an upright position with the feet placed shoulder width apart, connect the fingers and place the palm of the hand behind the head, this movement presses on the knee and groin. As for the series of movements and starts with downward pressure quickly with a half-squat position. It immediately moves down and quickly jumps up as high as possible with a half-squat landing.

Meanwhile, Mcneely and Sandler (2009: 97) say that; Lateral Box Push Offs exercise is standing next to the box and placing one foot completely on the box while other foot is fixed on the ground. when the foot is on the box, the lower leg should be perpendicular to the ground and parallel thighs to the floor creating 900 knee angles. swing both arms upward like explosive and push against box, jump as high as possible.

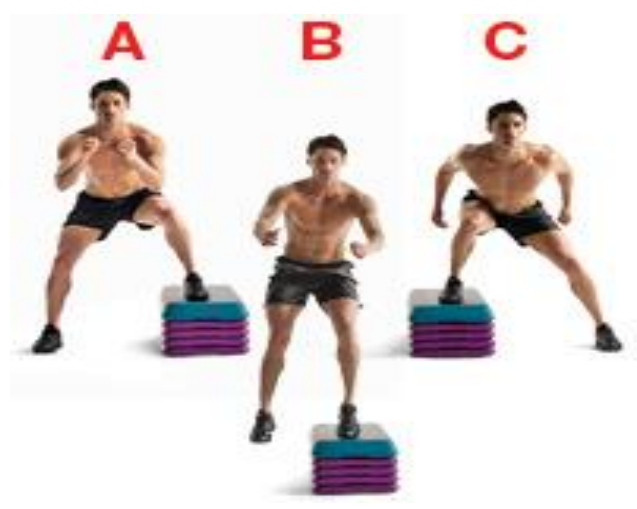

Figure 2. Lateral Box Push Offs Exercise Source; https://www.pliometrik+lateral+box+push+offs 


\section{Explanation:}

a) Stand to the side of the box and place the left foot above the box.

b) Push from the box using the left foot only and burst vertically as high as possible, arms forward for maximum height.

c) Land with the right foot on the box and left foot on the ground to the other side of the box.

d) Repeat from this side.

Implementation of the Lateral Box Push Offs exercise is done with both legs like a half squat with one foot above the box, jump as high as possible this will produce balanced leg muscle. Leg muscle strength has an important role to play sport activities such as jumping and so on. In the front kick movement, the presence of leg muscle strength has an important role to generate maximum power with explosive force. But from both forms of exercise the researchers wanted to prove the most effective and efficient form of exercise to increase the speed of the kick of the wushu athlete. The results of this study are expected to be useful as interested parties such as; trainers and athletes in an effort to improve the maximum performance as expected.

\section{Method}

This research uses quasi experiment method. The goal is to know whether there are any the effects of treatment between cause and effect that is comparing between the variables that are controlled (Sugiyono, 2011: 60). This study is intended to distinguish the results of the Split Squat Jump exercise and the Lateral Box Push Offs exercise as the independent variable, against the front kick speed as the dependent variable.

This study provides treatment to two groups, the Split Squat Jump exercise group and the Lateral Box Push Offs exercise group. Before the treatment is given, a preliminary test is performed to determine the experimental group, then the final test is given. This research uses the research design of two groups pre-test and post-test design (Arikunto, 1989).

This research was conducted in the field of football laboratory of Faculty of Sports Science, Padang State University. Frequency of exercise / treatment performed three times a week. The initial test (pre-test) is then continued by providing Split Squat Jump and Lateral Box Push Offs exercises. A total of 16 meetings conducted four times a week, and final test (post-test) on the last meeting.

The population of this study is the whole object to be studied. This is in accordance with the opinion that is said by Sugiono (2009: 117) that "population is a generalization region consisting of objects/subjects that have certain qualities and characteristics set by the researchers to be studied and then drawn conclusions. The population in this study is all Wushu athletes in FIK UNP.

\section{Table 1. Population Research}

\begin{tabular}{|c|l|c|}
\hline No & Population & Amount \\
\hline 1. & Man Athlete & 16 Athlete \\
\hline 2. & Woman Athlete & 5 Athlete \\
\hline \multicolumn{2}{|c|}{ Total } & 21 Athlete \\
\hline
\end{tabular}

Source. Sasana Wushu FIK UNP

Sampling in this research is by purposive sampling. According to Yusuf (2005: 205) "The sampling by purposive is based on certain objectives or considerations. Thus the sampling is determined on a predetermined purpose ". The sample in this study was determined only 16 male athletes, with the following considerations: (1) the difference of physical ability between the male 
athletes and the female athletes, (2) the number of female athletes is less than the male athletes, (3) the limited time, 4) limited manpower as well as funding, so the sample in this study are 16 male athletes.

Treatment in the form of an exercise process for each group lasting for 6 weeks, which starts in the first week of April until the end of May 2016. Training is done 3 times a week on Mondays, Wednesdays and Fridays. The process of training is done in the field of laboratory FIK UNP, which is used as training place of Wushu athletes FIK UNP. This exercise is provided by coaches and assistant trainers who work with researchers.

The research instrument is using front kicks with petching targets of 10 times and the data taken is in the form of time by using stopwatch. This is in accordance with the opinion of Bompa (1994) that; in viewing the ability of Speed and Power it can be done with the frequency of exercise activities starting from 8 to 12 times. Data analysis using t test on significance level $\alpha=0.05$.

\section{Research result}

After requirements of the test analysis has done, next the hypothesis testing. The hypothesis proposed in this study consists of 3 submissions (1) There is a significant influence of Split Squat Jump Training on the front kick speed (tanti) Wushu athletes FIK UNP. (2) There is significant influence of Lateral Box Push Offs exercise on front kick speed (tanti) Wushu athlete FIK UNP. (3) There is a difference in the effect of the Split Squat Jump exercise and the Lateral Box Push Offs exercise against the front kick rate (tanti). For more details in testing this hypothesis can be seen in the following description:

\section{There is a significant influence of the Split Squat Jump Exercise on Front Kicking Speed (tanti) Wushu Athlete FIK UNP.}

The statistical test used in this hypothesis is $t$ Dependent Variable Test that is looking at the relation of influence from pre-test to post-test so it got the average count score in a group with significant level of $\alpha=0.05$, which result of the analysis show that:

Table 2. Summary of test results Group hypothesis 1

\begin{tabular}{|c|c|c|c|c|}
\hline Group 1 & Mean & SD & \multirow{2}{*}{$\mathrm{t}_{\text {count }}$} & \multirow{2}{*}{$\mathrm{t}_{\text {table }}$} \\
\hline Pre-test & 8,31 & 0,71 & \multirow{2}{*}{2,53} & \multirow{2}{*}{1,86} \\
\hline Post-test & 7,96 & 0,88 & \\
\hline
\end{tabular}

Based on table 3 it can be seen that $t_{\text {count }}(2.61)>t_{\text {table }}(1.86)$, thus it can be concluded that; the second hypothesis proposed in this study is acceptable, in other words that; the exercise of Lateral Box Push Offs gives a significant influence on the increase of front kick speed (tanti) of Wushu athlete FIK UNP.

\section{There is a significant influence of Lateral Box Push Offs Exercise on Front Kicking Speed (tanti) Wushu Athlete FIK UNP.}

The results of the second group data analysis can be seen in table 3 below; 
Tabel 3. Summary the results of hypothesis testing group 2

\begin{tabular}{|c|c|c|c|c|}
\hline Group 2 & Mean & $\mathrm{SD}$ & $\mathrm{t}_{\text {count }}$ & $\mathrm{t}_{\text {table }}$ \\
\hline Pre-test & 8,22 & 0,56 & \multirow{2}{*}{2,61} & 1,86 \\
\hline Post-test & 8,03 & 0,49 & \\
\hline
\end{tabular}

Based on table 3 it can be seen that $t_{\text {count }}(2.61)>t_{\text {table }}$ (1.86), thus it can be concluded that; the second hypothesis proposed in this study is acceptable, in other words that; the exercise of Lateral Box Push Offs gives a significant influence on the increase of front kick speed (tanti) of Wushu athletes FIK UNP. The increase in the average speed of the kick is 0.19 starting from the 8.22 average pre-test, after the treatment is treated to be faster at the post-test average of 8.03 .

\section{Split Squat Jump Training is Better than Lateral Training Box Push Offs Towards Front Kicking Speed (tanti) Wushu Athletes of FIK UNP.}

The results of the third hypothesis analysis can be seen in table 4 below;

Table 4. Summary of the results of the third hypothesis testing Split Squat Jump Exercise with Lateral Box PushOffs exercise.

\begin{tabular}{|c|c|c|c|c|}
\hline group & Mean & SD & $\mathrm{t}_{\text {count }}$ & $\mathrm{t}_{\text {table }}$ \\
\hline Group 1 & 7,96 & 0,88 & \multirow{2}{*}{0,19} & \multirow{2}{*}{1,86} \\
\hline Group 2 & 8,03 & 0,49 & & \\
\hline
\end{tabular}

Based on table 4 it can be seen that $t_{\text {count }}(0.19)<t_{\text {table }}(1.86)$, thus it can be concluded that; the third hypothesis in the study was rejected. In other words that; there is no difference in the influence between the Split Squat Jump exercise and the Lateral Box Push Offs exercise against the increased front kick (tanti) of Wushu athletes FIK UNP, so both methods can be used to train front-kick velocity.

However, when viewed from the average increase of Split Squat Jump training and Lateral Box Push Offs training on the front kick speed obtained an average increase of 0.34 for the practice of Split Squat Jump and equal to 0.19 for lateral box exercise push offs. Thus it can be concluded that the Split Squat Jump exercise is better than the practice of Lateral Box Push Offs against the increase in front kick speed (tanti) Wushu athletes of FIK UNP.

\section{Discuss}

1. Based on the results of the Split Squat Jump training data analysis can increase the speed of the front kick (tanti) Wushu athletes FIK UNP. The occurrence of this increase is allegedly caused by adaptations that increase the muscle ability of the Split Squat Jump training.These findings show and prove (James Radcliffe and Robert Farentinos 1985: 59), that the Split Squat Jump exercise is an exercise that has a special movement to increase the explosive power of the lower leg muscles which form of training leads to the form of Bound, Jump, and Hop. The Split Squat Jump exercise is a very practical type of exercise and has a very good effect on improving explosive power and can improve the speed of the athlete. Muscle contractions that 
occur in the type of exercise is very high, this can be seen when the split leg muscles are stretched and jump upwards, at the time of landing, legs open again. The weight held by the muscles in the legs at the time of landing from the leap to the open position with the shape of the front squats, will experience a strong contraction. Based on these explanations, it can be said Split Squat Jump exercise can increase leg muscle strength in performing a movement that can increase the speed of the front kick.

2. The result of the data analisys in group 2 also shows that the exercise of Lateral Box Push Offs can increase the speed of the front kick (tanti) Wushu Athletes FIK UNP.

These findings demonstrate and simultaneously prove the statement (exercises plyometric), that the practice of Lateral Box Push Offs is a plyometrics exercise and kalisteknik exercises whose main target is to improve gluteus muscle and next target of the quadriceps muscle, calf, hamstrings and outer thighs. Lateral Exercise Box Push Offs is one form of Plyometrics exercise that is used to increase the explosive power of the leg muscles and relate directly to the movement and increase the speed of the front kick. Muscle contractions that occur in the practice of Lateral Box Push Offs can be seen when the position of one foot on the floor and one foot above the jump box, the feet on the floor will make jumps and body position when the jump is above the box, the legs above the box landed on the side the box with the position of the foot swapping from its original position, always back to the starting position. Based on the explanation, it can be said that the type of exercise Push Offs Lateral Box is part of the Plyometric exercise which can increase the strength of all the muscles in the legs in doing a movement that can increase the speed of the front kick.

3. Based on the results of data analysis, there was no significant difference in influence between the Split Squat Jump exercise and the Lateral Box Push Offs exercise on the increase of front kick velocity (tanti) Wushu athlete FIK UNP. However, judging from the average increase in the Split Squat Jump Exercise is better than the practice of Lateral Box Push Offs against the increase in front kick speed (tanti) Wushu FIK UNP athlete.

Basically plyometric exercise produces an effect or effect on the athlete's physical condition when done with programmed and exercises that connect the movement of speed and power to produce explosive movements. Squat Jump Exercises and Lateral Box Push Offs Exercises are a type of exercise to increase the strength of the leg muscles in performing a movement that can increase the speed of the front kick although different forms of execution.

Based on the findings, the practice of Split Squat Jump and Lateral Box Push Offs both affects the increased speed of the athlete's front kick, and between the two exercises is a more effective Split Squat Jump exercise to increase the front kick athlete's speed, this is due to the Split Squat Jumps have a jumping motion upward and then landed with open legs like front horses that are almost the same as the front-kick technique movement that targets the forward kick with the forwardfacing position, so the Split Squat Jump exercise has more speed improvement than exercise Lateral Box Push Offs whose movements jump up and one leg landed under the side of the box (lateral box).

\section{Conclusion}

1. Split Squat Jump training can increase the front kick speed (tanti) of wushu athletes in FIK UNP.

2. Lateral Exercise Box Push Offs can increase the front kick speed (tanti) of wushu athletes in FIK UNP.

3. There is no significant difference of influence between the Split Squat Jump training and the Lateral Box Push Offs exercise against the increased front kick speed of the Fik UNP wushu 
athlete. However, when viewed from the average value, the Split Squat Jump exercise is more effective to increase the speed of the front kick (tanti) wushu athletes in FIK UNP.

\section{Suggestion}

1. It is expected that Wushu coaches, especially Wushu FIK UNP trainers, can use the Plyometrics Training method which is Split Squat Jump training and Lateral Box Push Offs practice to improve front kicking speed (tanti) Wushu athletes in FIK UNP.

2. It is hoped for Fik UNP wushu athletes to be able to carry out Split Squat Jump training and Lateral Box Push Offs exercises, since both methods can improve the speed of the front kick (tanti).

3. It is expected that the next researcher will be able to develop this research to other sports, in order to be used for all audiences.

4. To Wushu club especially in padang city is expected to give Split Squat Jump training and Lateral Box Push Offs practice to increase front kick speed (tanti).

\section{REFERENCES}

Arikunto, Suharsimi. (1989). Metodologi Penelitian. Jakarta : Rineka Cipta (2007). Manajemen Penelitian. Jakarta: Rineka Cipta

Bompa T. O. (1999). Periodizations Theory and Methodology of Training (cetakan kedua). Canada: Mosaic press.

Chu. Donal. A. 1992. Jumping Into Plyometric. California : Leisure Press Champaign Illionis.

http://www. workoutbox.com/ exercises/ leg-exercises/split-squat-jump/

http://wushu-fouad.skyrock.com/ 3000482583-combats-wushusanda.html

Kurniawan, Feri. 2012. Buku Pintar Olahraga. Jakarta timur: Laskar Aksara.

Lubis, Johansyah. ( 2004 ). Pencak Silat Panduan Praktis. Devisi Buku Sport. Jakarta : PT Raja Grafindo Persada.

Radcliffe, J.C \& Farentinos, R.C. (1985). Plyometrics Explosive Power Training. 2nd ed. Champaign, Illionis: Human kinetics Published, Inc.

Sugiono, P. (2009). Perbedaan Pengaruh Latihan Split Jump dengan Latihan Squat Jump Terhadap Kecepatan Tendangan Depan/Cechuitui Atlet Wushu Naga Sakti Pematang Siantar. Semarang : Lembaga Penelitian Tesis UNNES.

Sugiyono. 2011. Statistic untuk Penelitian. Bandung: Alfabet

Sugiono. 2009. Metodelogi Penelitian Pendidikan. Bandung: Alfabet 
Wong Kiew Kit. (2003). The Art of Shaolin Kungfu, Rahasia Kungfu Untuk Beladiri, Kesehatan dan Pencerahan. Jakarta : PT. Elex Media Komputindo. 